\title{
Movement for Movement: a practical insight into embedding physical activity into the undergraduate medical curriculum exemplified by Lancaster Medical School
}

Ann B Gates ${ }^{1,2}$, Michelle G Swainson ${ }^{3}$, Rachel Isba ${ }^{3}$, Robert G Wheatley ${ }^{3}$, Fiona A Curtis ${ }^{3}$

\footnotetext{
${ }^{1}$ School of Health Sciences, University of Nottingham, Derby, UK

${ }^{2}$ Faculty of Sport, Health and Wellbeing, Plymouth Marjon University, Plymouth, UK

${ }^{3}$ Lancaster Medical School, Lancaster University, Lancaster, UK
}

Competing Interests: Ann B. Gates BPharm (Hons) MRPharmS is an Honorary Visiting Professor Plymouth Marjon University, Honorary Associate Professor at The University of Nottingham, a World Heart Federation Emerging Leader's Programme 2014, Associate Editor for The British Journal of Sports Medicine, a Certified NHS Change Agent and Founder and CEO of Exercise Works! MGS has contributed to the 2018 update of Movement For Movement resources. RI, RW and FAC have no competing interests. MGS.

Contributorship statement: ABG was the main author for final submission. MGS produced the initial manuscript, provided final review and created the infographic produced for this article. RI and FAC provided both written contribution and editorial review. FAC and RGW have been key to the planning and practical implementation of these resources, identification of good practice examples and provided further reviews of the content and style.

Twitter: @exerciseworks @mgswainson 
Corresponding author:

Michelle Grace Swainson PhD

Lancaster Medical School, Faculty of Health and Medicine, Lancaster University, Lancaster, LA1 4YD, UK

m.swainson1@lancaster.ac.uk 


\section{Background}

Getting people active and staying active is a major implementation challenge[1]. Despite international and national strategic intent; most countries fall woefully short on delivery[2]. The objectives of the 2018 WHO Global Action Plan for Physical Activity (GAPPA) clearly require improved education and communication to patients, communities and society on the benefits of physical activity (PA).

The Movement For Movement "community of practice" (CoP) was specifically created to deliver this complex, interrelated, system change[3].

\section{What is The Movement For Movement?}

Movement For Movement[3] embeds PA into the undergraduate healthcare curriculum[4, 5] and provides current, clinically valuable, evidence-based resources developed by: curators, authors, peer reviewers, student reviewers, and endorsed by the UK Council of Deans of Health. These resources are free to providers of undergraduate medical and healthcare education to support capacity building in the healthcare workforce. An implementation plan in a sample of English medical schools (funded by Public Health England/Sport England in $2017 / 18$ ) is complete[6].

This work is recognised as a UK best practice exemplar by the 2018 WHO Europe Physical Activity Fact Sheets[7] and the 2018 WHO Europe Physical Activity in the Health Sector report[8]. There is also considerable ongoing collaboration to deliver further strategic support and leadership focussing on the valuable "social capital" that health care professionals provide across all the GAPPA objectives and specifically the social determinants of health.

Lancaster University Medical School's novel approach to embedding PA in the curricula 
Lancaster Medical School pioneered the full implementation of the Movement for Movement resources and is empowering future doctors with the knowledge and skills to positively impact individual and population health. Each student can and should make every contact count and make every influence matter across their future career. This amounts to half a million opportunities to improve physical activity, per doctor, per medical school.

\section{Sharing good practice - a practical guide from Lancaster}

The first step to embedding PA into an undergraduate curriculum is to access the Movement for Movement resources (sent to all UK medical schools each year). These are fully integrated into the existing virtual learning environment/s for staff and students. Engaging the Dean and curricula leads supports successful implementation. With students - provide the generic resources in year 1 and specific resources in years $2 / 3$ to enhance learning on noncommunicable diseases (NCD). Assess and examine PA knowledge and communication skill competencies, capabilities and confidence.

The provision of resources does not necessarily lead to engagement; instead students need to be directed to them by including specific PA-related learning outcomes and communication assessments. Practical insights recommend that links and references to the resources are embedded within lectures and workshops, or better still include one dedicated PA lecture per NCD or societally challenging issue (Supplementary file). As an example, modules at Lancaster Medical School adopt problem-based learning (PBL) scenarios, each focusing on a major NCD or age-related condition, whilst addressing associated co-morbidities and psycho-social challenges.

\section{Lessons learnt at Lancaster Medical School}

Leadership and action were fundamental to successful implementation. Lancaster were strongly commended in the commission report[6] for embedding the resources at all levels of the curriculum and achieving all framework criteria. 


\section{Lessons learnt across the English sample of Medical Schools}

12 out of a sample of 16 medical schools have provided evidence that there is now access to resources and teaching on PA. Knowledge transfer, assessment and examination of key clinical skills regarding brief intervention on PA and the wider public health determinants are also being explored by each University (and collectively by the UK Medical Schools Assessment Alliance). The lesson is that direct contact with each curricula team and skilled implementation support, works.

\section{Future for the Movement for Movement}

Empowering medical schools, schools of health, and students to access and engage with the resources is an ongoing priority. With many English medical schools now teaching, assessing and examining on PA in the curriculum: the future is indeed bright. We thank the Lancaster University Medical School for their example and all the other English medical schools and UK schools of health for their leadership and work.

There is increasing access to the resources world-wide for example in the USA, Canada, Australia and low and middle-income continents such as Africa and South America through a variety of online educational tools and student courses.

Undergraduate medical and health education on making every contact count and every influence matter for PA is happening in England[7, 8]. 120,000 healthcare students across the UK: competent, capable and confident of delivering physical activity influence is our goal.

But the future for embedding PA in the curriculum is very bright: and going global!

For access to the Movement for Movement resources, contact Ann Gates. 
Supplementary file Infographic

Acknowledgements ABG thanks all the deans of medicine and health, faculty staff, students and fellow PA advocates in England for their support for the project and their facilitation of a warm welcome at each of the visits. Thanks, and recognition are also due to PHE and Sport England for the commission to teach PA to the healthcare workforce. A special mention is warranted for the UK Council of Deans of Health for leading on the work with HEls. But lastly, we extend our heartfelt appreciation to all the past and present contributors to the physical activity resources, the \#MovementForMovement community of practice team of over 40 authors and nearly 30 peer reviewers.

Funding The authors have not declared a specific grant from any funding agency in the public, commercial or not-for-profit sectors. ABG was originally commissioned and funded by PHE and Sport England.

\section{References}

1 Global action plan on physical activity 2018-2030: more active people for a healthier world. Geneva: World Health Organization; 2018. Licence: CC BY-NC-SA 3.0 IGO. http://apps.who.int/iris/bitstream/handle/10665/272722/9789241514187-eng.pdf (accessed 11 Nov 2018).

2 Guthold R, Stevens GA, Riley LM, et al. Worldwide trends in insufficient physical activity from 2001 to 2016: a pooled analysis of 358 population-based surveys with 1.9 million participants. Lancet Glob Health 2018;6(10):e1077-E1086. Published Online First: 4 Sep 2019. doi.org/10.1016/S2214-109X(18)30357-7.

3 Gates AB, Kerry R, Moffatt F, et al. Movement for movement: exercise as everybody's business? Br J Sports Med 2017;51(10):767-8.

4 Gates AB. Training tomorrow's doctors, in exercise medicine, for tomorrow's patients. $\mathrm{Br} \mathrm{J}$ Sports Med 2015;49:207-208. 
5 Gates AB. Making every contact count for physical activity-for tomorrow's patients: the launch of the interdisciplinary, undergraduate, resources on exercise medicine and health in the UK. Br J Sports Med 2016;50:322-323.

6 Gates AB, Ritchie IK, Moffatt F, et al. Leadership in physical activity: is this the currency of change in the student healthcare curriculum? Br J Sports Med. Published Online First: 23 June 2018. doi.org/10.1136/bjsports-2018-099587.

7 WHO Europe Physical activity country factsheets 2018. http://www.euro.who.int/en/healthtopics/disease-prevention/physical-activity/data-and-statistics/physical-activity-factsheets/physical-activity-country-fact-sheets/united-kingdom-of-great-britain-and-northernireland (accessed 11 Nov 2018).

8 WHO Europe Physical Actvity in the Health Sector Report 2018.

http://www.euro.who.int/_data/assets/pdf_file/0008/382337/fs-health-eng.pdf?ua=1 (accessed 11 Nov 2018). 


\section{Programme Card}

\begin{tabular}{|c|c|}
\hline Country & $\begin{array}{l}\text { An England wide educational initiative targeting medical schools } \\
\text { and UK schools of health }\end{array}$ \\
\hline Target population & $\begin{array}{l}\text { Undergraduate students on medicine and healthcare degree } \\
\text { programmes }\end{array}$ \\
\hline PA promotion & $\begin{array}{l}\text { The Movement for Movement (M4M) curriculum promotes } \\
\text { physical activity (PA) through medical education, with specific } \\
\text { guidance provided for various noncommunicable diseases }\end{array}$ \\
\hline Investments for PA & $\begin{array}{l}\text { Encourages communication and public education (investment 1), } \\
\text { healthcare and health education (investment } 4 \text { ), and education } \\
\text { (investment 5) }\end{array}$ \\
\hline Sectors & $\begin{array}{l}\text { Available to Universities and undergraduate students in UK } \\
\text { medical and healthcare education }\end{array}$ \\
\hline $\begin{array}{l}\text { Estimated programme } \\
\text { reach }\end{array}$ & $\begin{array}{l}\text { M4M resources have been offered to all UK Medical Schools and } \\
\text { Schools of Health with a reach of } 120,000 \text { students. This set of } \\
\text { presentations and associated resources are planned for } \\
\text { dissemination into Europe with future ambition to reach a global } \\
\text { audience. }\end{array}$ \\
\hline $\begin{array}{l}\text { What is special about } \\
\text { the program? }\end{array}$ & $\begin{array}{l}\text { Embedding PA in the undergraduate healthcare curriculum is an } \\
\text { important step to building capacity in the future workforce to promote } \\
\text { PA, with every contact. This is the first development of PA for } \\
\text { health resources that can be implemented into UK } \\
\text { undergraduate medical and health programmes. }\end{array}$ \\
\hline Key contact & $\begin{array}{l}\text { Michelle Swainson m.swainson1@lancaster.ac.uk } \\
\text { Ann Gates annbgates@googlemail.com for access to the } \\
\text { resources }\end{array}$ \\
\hline $\begin{array}{l}\text { Programme } \\
\text { website/twitter/facebook }\end{array}$ & $\begin{array}{l}\text { Council of Deans } \\
\text { https://councilofdeans.org.uk/2017/11/updated-resources- } \\
\text { launched-to-support-teaching-of-physical-activity-for- } \\
\text { undergraduate-health-care-students/ } \\
\text { Blog editorials } \\
\underline{\text { https://bjsm.bmi.com/content/50/6/322 }} \\
\underline{\text { https://bjsm.bmi.com/content/49/4/207 }} \\
\underline{\text { https://bjsm.bmi.com/content/early/2018/06/26/bjsports-2018- }} \\
\underline{099587}\end{array}$ \\
\hline
\end{tabular}




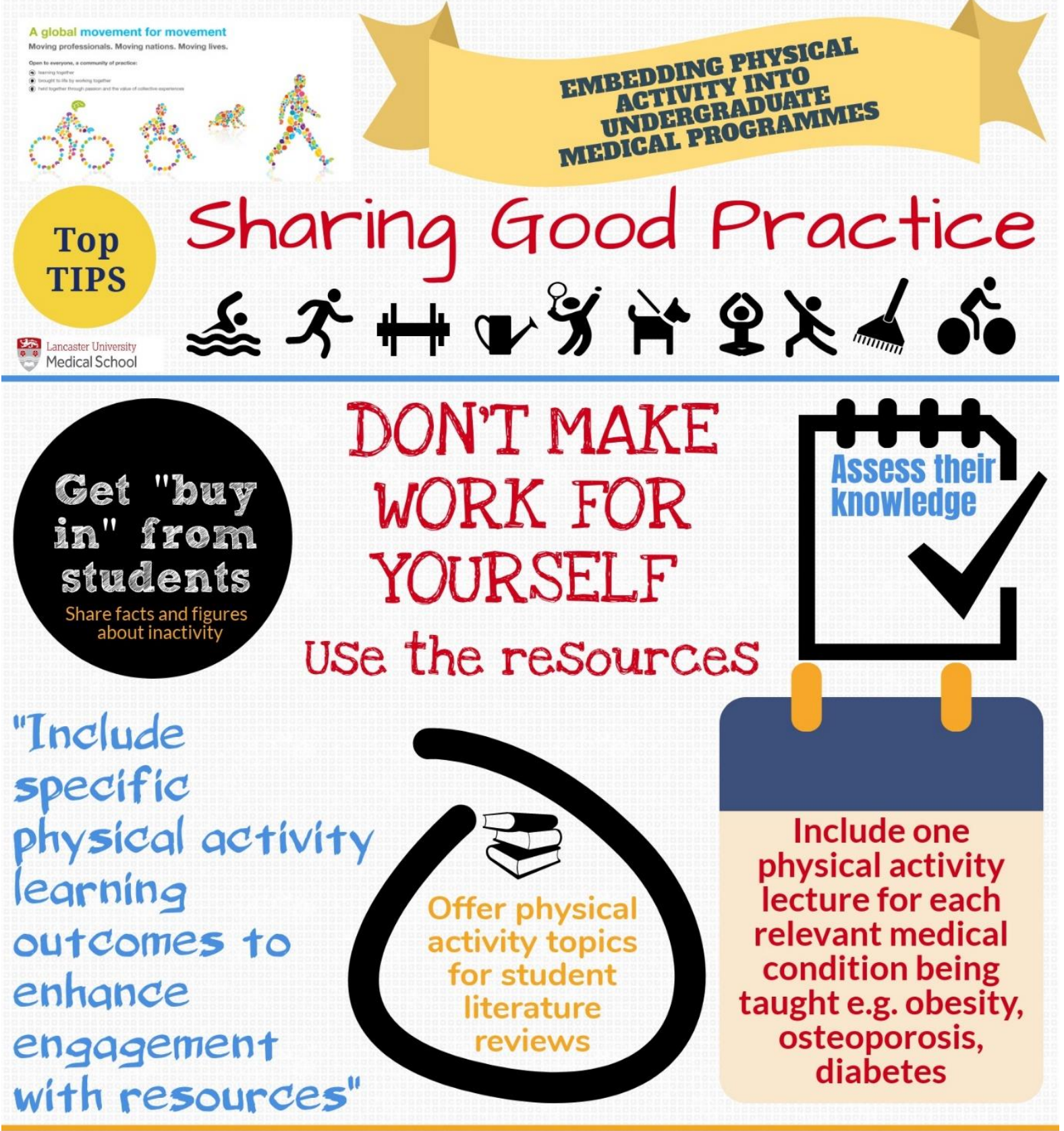

"At Lancaster ... the

inclusion of physical activity into our curriculum was deemed highly important and valuable to ensure we are generating excellent future doctors who can appropriately deal with the challenges of modern medicine"

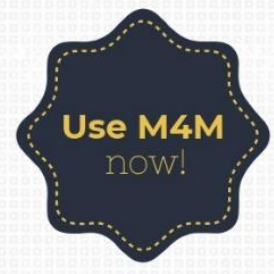

Designed by @mgswainson

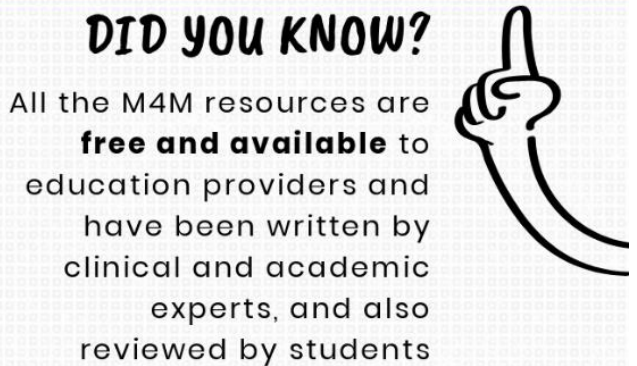

reviewed by students 